\title{
CT Determination of Fractional Flow Reserve in Coronary Lesions
}

\author{
András Mester ${ }^{1}$, Monica Chițu², Nora Rat², Diana Opincariu¹, Lehel Bordi', Alexandra Stănescu', \\ Marius Orzan², Tiberiu Nyulas², Imre Benedek ${ }^{1,2}$ \\ ${ }^{1}$ Center of Advanced Research in Multimodality Cardiac Imaging, Cardio Med Medical Center, Tîrgu Mureș, Romania \\ 2 University of Medicine and Pharmacy, Tîrgu Mureș, Romania
}

\section{CORRESPONDENCE}

\begin{abstract}
Monica Chițu
Str. Gheorghe Marinescu nr. 38

540139 Tîrgu Mureș, Romania

Tel: +40 265215551

E-mail: iuliachitu@yahoo.com
\end{abstract}

\section{ARTICLE HISTORY}

Received: 3 October, 2016

Accepted: 27 October, 2016

István Kovács • Str. Gheorghe Marinescu nr. 38 540139 Tîrgu Mureș, Romania. Tel: +40 265215551. E-mail: kov_istvan@yahoo.com

András Mester • Str. 22 Decembrie 1989 nr. 76 540124 Tîrgu Mureș, Romania. Tel: +40 265217333. E-mail: andras.mester@yahoo.com

Nora Rat • Str. Gheorghe Marinescu nr. 38, 540139 Tîrgu Mureș, Romania. Tel: +40 265215 551. E-mail: ratnora@gmail.com

Diana Opincariu • Str. 22 Decembrie 1989 nr. 76 , 540124 Tîrgu Mureș, Romania. Tel: +40 265217333. E-mail: diana.opincariu@yahoo.ro

Lehel Bordi • Str. 22 Decembrie 1989 nr. 76, 540124 Tîrgu Mureș, Romania. Tel: +40 265217 333. E-mail: bordi_lehel@yahoo.com

Alexandra Stănescu • Str. 22 Decembrie 1989 nr. 76 540124 Tîrgu Mures, Romania. Tel: +40 265217333. E-mail: alexandrastanescu90@gmail.com

Marius Orzan • Str. Gheorghe Marinescu nr. 38 540139 Tîrgu Mureș, Romania. Tel: +40 265215551. E-mail: orzan_marius@yahoo.com

Tiberiu Nyulas • Str. Gheorghe Marinescu nr. 38 540139 Tîrgu Mureș, Romania. Tel: +40 265215551. E-mail: tiberiu.nyulas@gmail.com

Imre Benedek • Str. Gheorghe Marinescu nr. 38 540139 Tîrgu Mureș, Romania. Tel: +40 265215551.

E-mail: imrebenedek@yahoo.com

\begin{abstract}
Invasively determined fractional flow reserve (FFR) represents the gold-standard method for the functional evaluation of coronary lesions. Coronary computed tomography angiography (CCTA) provides characterization of the coronary anatomy, with important morphological information on the atherosclerotic plaques, but does not offer a hemodynamic evaluation of coronary artery lesions. CT evaluation of FFR (FFRCT) is a new noninvasive diagnostic method, which provides anatomical and functional assessment of the whole coronary tree, based on computational techniques, with no more radiation or hyperemic agent administration compared with routine CCTA. Recent studies demonstrated the safety and accuracy of FFRCT and its therapeutic use and cost benefits in real-world clinical use.
\end{abstract}

Keywords: FFRCT, cardiac computed tomography angiography, coronary angiography, hemodynamics, revascularization, $\mathrm{PCl}$

\section{INTRODUCTION}

Numerous diagnostic modalities are available for analyzing the anatomical severity of a coronary stenosis. Coronary computed tomography angiography (CCTA) and invasive coronary angiography (ICA), combined with modern imagining tools including optical coherence tomography (OCT) and intravascular ultrasound (IVUS), are useful methods for identifying anatomically significant lesions, but none of these methods offer information about their hemodynamic consequence. ${ }^{1}$

In current clinical practice, fractional flow reserve (FFR) - the maximum blood flow through a stenosed coronary artery, determined invasively as the ratio between distal coronary artery and intra-aortic pressure during maximum hyperemia - is used for the functional estimation of intermediate coronary artery stenoses. An FFR index of $<0.8$ is considered functionally significant. ${ }^{2}$ The European guidelines for myocardial revascularization indicate FFR as a class Ia recommendation for identifying functional coronary lesions in stable patients 
without evidence of ischemia and a class IIa recommendation for the decision-making process of either opting for revascularization or pharmacological treatment. ${ }^{3}$

\section{USEFULNESS OF FFR IN CLINICAL PRACTICE}

Several trials have proved the clinical utility of FFR in guiding the treatment decision. Pijls et al. presented the results of the DEFER trial (Deferral of PTCA versus performance of PTCA), which enrolled 325 subjects with single-vessel coronary artery stenosis. FFR was performed for all lesions. If the FFR ratio was $>0.75$, the patient was randomized to the Defer group $(n=91)$, with deferral from PTCA, or to the Perform group $(n=90)$, where PTCA was performed immediately. If the FFR was $<0.75$, the patient was included in the Reference group ( $\mathrm{n}$ $=144$ ), where PTCA was performed as planned. Clinical follow-up was obtained at 5-years, and no differences were recorded between the Defer and Perform groups regarding the event-free survival rates $(80 \%$ vs. $73 \%$; $p=$ 0.52 ), but these were higher in the reference group (63\%; $\mathrm{p}=0.03)$. The rates of cardiac mortality and myocardial infarction did not differ between the two groups (Defer $-3.3 \%$ vs. Perform $-7.9 \%$; $=0.21$ ), but were meaningfully inferior in the Reference group (15.7\%; $\mathrm{p}=0.003 \mathrm{vs}$. the Defer and Perform groups). ${ }^{4}$ This study concluded that deferral from PCI in patients with FFR $>0.75$ is safe, with good long-term clinical outcomes, and that FFR can recognize patients who will benefit from PTCA. Another benchmark FFR study was performed by Pijls et al. in the FAME trial (Fractional Flow Reserve Versus Angiography for Multivessel Evaluation), which investigated the clinical outcome of FFR-guided PTCA versus the standard, angiography-guided PTCA in patients with multi-vessel coronary atherosclerosis. During the 2-year follow-up, the percentage of deaths and myocardial infarctions (MI) were inferior in the FFR-guided PTCA with drug-eluting stents group ( $12.9 \%$ vs. $8.4 \%$; $\mathrm{p}=0.02) .{ }^{5}$ The 5 -year followup proved that FFR-guided PCI is safer. ${ }^{6}$ Further inquiry was performed in the FAME 2 trial, which included 1,220 patients scheduled for DES-PCI and compared the longterm clinical outcome of FFR-guided PCI versus optimal pharmacological therapy in patients with stable coronary artery disease (CAD). Patients with at least 1 functional lesion (FFR $\leq 0.8$ ) were randomized to PCI with optimal drug therapy or pharmacological treatment alone $(\mathrm{n}=$ 888). Patients with FFR $>0.8$ were included in the registry group and received optimal medical treatment alone ( $\mathrm{n}=$ 332). At 2-year follow-up, there was no substantial difference between the two randomized groups regarding the mortality and MI rates, but there was a substantial difference in the rate of emergency revascularization $(4.0 \% \mathrm{vs}$. $16.3 \%$; $\mathrm{p}<0.001) .7,8$

Multiple clinical trials have proven that the routine use of FFR (as gold-standard for the evaluation of hemodynamic significance of a coronary lesion) in guiding and optimizing PCI has improved the clinical outcome of patients and is currently one the most solid recommendations in current guidelines for a revascularization. ${ }^{9}$

\section{THE NEED FOR NONINVASIVE FFR DETERMINATION}

With the evolution of noninvasive imaging techniques in the last decade, CCTA became an important and reliable diagnostic tool for identifying low- and intermediate-risk CAD patients. ${ }^{10}$ Current ESC guidelines give CCTA a Class IIa recommendation with $\mathrm{C}$ level of evidence in patients with intermediate risk for CAD as a substitute for stress imaging techniques, given its high specificity and sensitivity. ${ }^{11-13}$ CCTA also demonstrated its reliability in the long-standing follow-up period of these individuals, as its high negative predictive value (NPV) can rule out longterm adverse events. ${ }^{14,15}$

Although CCTA can provide accurate $3 \mathrm{D}$ anatomic evaluation of the coronary arteries, determining the extent of luminal stenosis with plaque morphology characterization, numerous studies comparing CCTA- and ICA- assessed stenoses with invasive FFR determination demonstrated that the severity of coronary lesions does not always reflect the hemodynamic significance of a plaque. ${ }^{16-19}$ Meijboom et al. evaluated 89 lesions which caused $\geq 50 \%$ luminal stenosis assessed by CCTA and concluded that only $49 \%$ of these lesions were functionally significant, with a measured FFR $<0.75 .{ }^{20}$

Having these aforementioned tools, the development of a noninvasive technique that is able to offer both anatomical and functional evaluation of coronary lesions was imperative.

\section{THE CONCEPT OF FFRCT}

Fractional flow reserve derived from CCTA (FFRCT) is calculated using the same images as for the reconstruction of coronary arteries, without additional radiation exposure, acquisition protocol modifications or administration of hyperemic agents, using computational flow dynamics and can be determined in any point of the coronary artery system..$^{21}$

Currently two methods are available for determining FFRCT. The first one is based on an off-site supercomputer 
system analysis developed by HeartFlow Inc. (Redwood City, California, USA), which provides 3D modeling anatomical and functional evaluation of the whole coronary tree in approximately 1 or 2 days. The second one is an on-site workstation by Siemens (Forchheim, Germany), which provides $1 \mathrm{D}$ anatomical and functional analysis. ${ }^{22}$

The calculation for FFRCT requires: (A) a patient-specific anatomic model of the coronary artery system, obtained and processed (with segmentation algorithms, luminal boundary extraction of the main and side branches, identifying and analyzing coronary plaques in every artery, followed by generation of a geometric modeling mash fitted to the segmented data) from the recorded CCTA images; ${ }^{23,24}$ (B) a physiological model of the coronary blood flow, which requires the CCTA determination of the myocardial wall volume, the coronary resistance of each vessel (which is inversely proportional to the dimension of the artery), the pressure in the aorta (approximated from the average brachial artery pressure), and simulation of a maximum hyperemic state, when the resting microcirculation resistance is reduced; (C) a numerical equation to analyze the laws that govern fluid dynamics. These computations can be done by modeling fluid dynamics using the NavierStokes equations. ${ }^{24}$

Good-quality CCTA images are essential for FFRCT determination, as all computations are based on the acquired images. Appropriate patient selection and preparation is necessary for reduction of technical errors and artifacts. Even with recent advanced techniques, 10-13\% of patients included in large studies were excluded due to poor image quality.22

\section{ACCURACY OF FFRCT}

Several multi-center studies were conducted in the past years for assessing the diagnostic precision of FFRCT compared to the standard, invasively measured FFR..$^{25-27}$

A meta-analysis on three prospective multi-center FFRCT trials (NXT - Analysis of Coronary Blood Flow Using CT Angiography: Next Steps; DISCOVER-FLOW - Diagnosis of Ischemia-Causing Stenoses Obtained via Noninvasive Fractional Flow Reserve, and DeFACTO Determination of Fractional Flow Reserve by Anatomic Computed Tomographic Angiography) was recently published by $\mathrm{Li}$ et al., analyzing the diagnostic accurateness of FFRCT compared to invasively determined FFR (gold standard) and CCTA. The meta-analysis concluded that FFRCT demonstrated a high diagnostic capacity in determining coronary ischemia, with improved accuracy and specificity compared to CCTA. FFRCT may also reduce the false-positive results for patients with functionally non-significant lesions. ${ }^{28}$

The most recent and also largest NXT study, which included 254 patients revealed a significantly higher diagnostic accuracy for FFRCT compared to CCTA alone, with a higher specificity ( $79 \%$ vs. $34 \%$, p <0.001) and similar sensitivity ( $86 \%$ vs. $94 \%, p=$ NS). The link between FFRCT and FFR was also more significant than in previous studies. $^{27}$

Severe calcifications can alter the acquisition of CCTA images, with lower specificity and sensitivity causing a reduction in its diagnostic accuracy. In patients with an Agatson score of $>400-600$, the specificity of CCTA can drop down to $35-48 \% .{ }^{29,30}$ In a substudy of the NXT trial for patients with Agatson scores of over 400, no significant drop in accuracy, sensitivity and specificity was recorded in the FFRCT group compared to the CCTA group (75\%, $88 \%$ and $69 \%$ vs. $44 \%, 94 \%$ and $23 \%$, respectively). ${ }^{27}$ This benefit was maintained at higher Agatson scores in favor of FFRCT compared to CCTA alone. ${ }^{31}$

In a study that analyzed 44 patients with pre- and postvirtual PCI FFR values using computational fluid dynamics, Kim et al. detected a $96 \%$ sensitivity with a $100 \%$ specificity of CT-derived FFR. Thus, FFRCT may be useful for identifying patients who may benefit from revascularization and for prediction and optimization of PCI outcomes. ${ }^{32-34}$

\section{CLINICAL BENEFITS OF FFRCT}

In the recent PLATFORM trial (Prospective Longitudinal Trial of FFRCT: Outcome and Resource Impacts), which enrolled 584 patients with stable CAD, Hlatky et al. assessed the outcomes and resource use of FFRCT compared to other invasive and noninvasive techniques for a 90-day follow-up period. Seventy-three percent of patients that had been referred directly for ICA, had no significant coronary lesions ( $>50 \%$ stenosis), compared to only $12 \%$ in the FFRCT group. FFRCT results changed the therapeutic approach in $61 \%$ of cases, with cancelling of invasive diagnostic procedures, but the rate of revascularization by PCI or coronary artery bypass grafting was not significantly different between the two study lots $(31.6 \%$ in the ICA group vs. $28.5 \%$ in the FFRCT group). No MACE were registered in subjects in whom ICA was different based on the FFRCT results. ${ }^{35,36}$

A substudy of the PLATFORM trial assessed the costs and quality of life for patients undergoing FFRCT compared to other invasive and noninvasive techniques for a 90-day follow-up period. FFRCT was associated with bet- 
ter improvement in quality of life compared to other noninvasive techniques. FFRCT costs and resource use were $20 \%$ lower compared to ICA during the follow-up period. ${ }^{37}$

\section{CONCLUSIONS}

Among the current noninvasive diagnostic techniques, FFRCT represents the only reliable method for anatomical and functional assessment of CAD patients. There are no current guideline recommendations on the use of FFRCT, but current studies have demonstrated the safety and usefulness of this new technique. FFRCT can reduce the number and cost of unnecessary invasive diagnostic procedures and can provide useful information on the decision for revascularization and optimization of treatment. Further studies are required for the elaboration of guideline recommendations.

\section{CONFLICT OF INTEREST}

Nothing to declare.

\section{ACKNOWLEDGEMENT}

This research was supported via the research grant no. 103545/2016, contract number 43/05.09.2016, entitled "High performance multimodal MRI/CT imaging platform, for applications in computational medicine, nanoparticles and hybrid imaging for the research of atherothrombotic disorders - CARDIO IMAGE" financed by the Romanian Ministry of European Funds, the Romanian Government and the European Union.

\section{REFERENCES}

1. Meijboom WB, Meijs MF, Schuijf JD, et al. Diagnostic accuracy of 64-slice computed tomography coronary angiography: a prospective, multi-center, multivendor study. J Am Coll Cardiol. 2008;52:2135-2144.

2. Pijls NH, De Bruyne $B$, Peels $K$, et al. Measurement of fractional flow reserve to assess the functional severity of coronary-artery stenoses. $N$ Engl J Med. 1996;334:1703-1708

3. Windecker S, Kolh P, Alfonso F, et al. 2014 ESC/EACTS guidelines on myocardial revascularization: the task force on myocardial revascularization of the European society of cardiology (ESC) and the European association for cardio-thoracic surgery (EACTS)developed with the special contribution of the European association of percutaneous cardiovascular interventions (EAPCI). Eur Heart J. 2014;35:2541-2619.

4. Pijls NH, van Schaardenburgh P, Manoharan G, et al. Percutaneous coronary intervention of functionally nonsignificant stenosis: 5-year follow-up of the DEFER study. J Am Coll Cardiol. 2007;49:2105-2111.

5. Pijls $\mathrm{NH}$, Fearon WF, Tonino PA, et al. Fractional flow reserve versus angiography for guiding percutaneous coronary intervention in patients with multivessel coronary artery disease: 2-year follow-up of the FAME (Fractional Flow Reserve Versus Angiography for Multivessel Evaluation) study. J Am Coll Cardiol. 2010;56:177-184.

6. van Nunen LX, Zimmermann FM1, Tonino PA, et al. Fractional flow reserve versus angiography for guidance of $\mathrm{PCl}$ in patients with multivessel coronary artery disease (FAME): 5-year follow-up of a randomized controlled trial. Lancet. 2015;386:1853-1860.

7. De Bruyne B, Pijls NH, Kalesan B, et al. Fractional flow reserve-guided $\mathrm{PCl}$ versus medical therapy in stable coronary disease. $N$ Engl J Med. 2012;367:991-1001.

8. De Bruyne B, Fearon WF, Pijls $\mathrm{NH}$, et al. FAME 2 Trial Investigators Fractional flow reserve-guided $\mathrm{PCl}$ for stable coronary artery disease. $\mathrm{N}$ Engl J Med. 2014;371:1208-1217.

9. Toth GG, Johnson NP, Jeremias A, et al. Standardization of Fractional Flow Reserve Measurements. J Am Coll Cardiol. 2016;68:742-753.

10. Benedek I, Benedek T. MultisliceAngio Computed Tomography in the Diagnosis of Cardiovascular Diseases. Editura Universitatii, Oradea; 2014.

11. Stefanini GG, Windecker S. Can Coronary Computed Tomography Angiography Replace Invasive Angiography? Circulation. 2015;131:418426.

12. Chow BJ, Freeman MR, Bowen JM, et al. Ontario multidetector computed tomographic coronary angiography study: field evaluation of diagnostic accuracy. Arch Intern Med. 2011;171:1021-1029.

13. Montalescot G, Sechtem U, Achenbach S, et al. 2013 ESC guidelines on the management of stable coronary artery disease: the Task Force on the management of stable coronary artery disease of the European Society of Cardiology. Eur Heart J. 2013;34:2949-3003.

14. Hamon M, Biondi-Zoccai GG, Malagutti P, et al. Diagnostic performance of multislice spiral computed tomography of coronary arteries as compared with conventional invasive coronary angiography: a meta-anatylis. J Am Coll Cardiol. 2006;48:1896-1910.

15. Pontone $\mathrm{G}$, Andreini $\mathrm{D}$, Bartorelli $\mathrm{AL}$, et al. A long-term prognostic value of CT angiography and exercise ECG in patients with suspected CAD. JACC Cardiovasc Imaging. 2013;6:641-650.

16. Maurovich-Horvat $\mathrm{P}$, Schlett $\mathrm{CL}$, Alkadhi $\mathrm{H}$, et al. The napkin-ring sign indicates advanced atherosclerotic lesions in coronary CT angiography. JACC Cardiovasc Imaging. 2012;5:1243-1252.

17. Tonino PA, Fearon WF, De Bruyne B, et al. Angiographic versus functional severity of coronary artery stenoses in the fame study fractional flow reserve versus angiography in multivessel evaluation. J Am Coll Cardiol. 2010;55:2816-2821.

18. Toth G, Hamilos M, Pyxaras S, et al. Evolving concepts of angiogram: fractional flow reserve discordances in 4000 coronary stenoses. Eur Heart J. 2014;35:2831-2838.

19. Rossi A, Papadopoulou SL, Pugliese F, et al. Quantitative computed tomographic coronary angiography: does it predict functionally significant coronary stenoses? Circ Cardiovasc Imaging. 2014;7:43-51.

20. Meijboom WB, Van Mieghem CA, van Pelt $N$, et al. Comprehensive assessment of coronary artery stenoses: computed tomography coronary angiography versus conventional coronary angiography and correlation with fractional flow reserve in patients with stable angina. J Am Coll Cardiol. 2008;52:636-643.

21. Zarins CK, Taylor CA, Min JK. Computed fractional flow reserve (FFRCT) derivated from coronary CT angiography. J Cardiovasc Transl Res. 2013;6:708-714

22. Nakanishi R, Budoff MJ. Noninvasive FFR derived from coronary CT angiography in the management of coronary artery disease: technology and clinical update. Vasc Health Risk Manag. 2016;12:269-278.

23. Taylor CA, Fonte TA, Min JK. Computational fluid dynamics applied to cardiac computed tomography for noninvasive quantification of fractional flow reserve: scientific basis. J Am Coll Cardiol. 2013;61:2233-2241.

24. Pang CL, Alcock R, Pilkington N, et al. Determining the haemodynamic significance of arterial stenosis: the relationship between CT angiography computational fluid dynamics, and noninvasive fractional flow reserve. Clin Radiol. 2016;71:750-757.

25. Koo BK, Erglis A, Doh JH, et al. Diagnosis of Ischemia-Causing Coronary Stenoses by Noninvasive Fractional Flow Reserve Computed From Coronary Computed Tomographic Angiograms. Results from the Prospective Multicenter DISCOVER-FLOW Study. J Am Coll Cardiol. 2011;58:1989-1997.

26. Min JK, Leipsic J, Pencina MJ, et al. Diagnostic accuracy of fractional flow reserve from anatomic CT angiography. JAMA. 2012;308:1237-1245.

27. Nørgaard BL, Leipsic J, Gaur S, et al. NXT Trial Study Group. Diagnostic performance of noninvasive fractional flow reserve derived from coronary computed tomography angiography in suspected coronary artery disease: the NXT trial (analysis of coronary blood flow using CT angiography: next steps). J Am Coll Cardiol. 2014;63:1145-1155.

28. Li S, Tang $X$, Peng L, Luo $Y$, et al. The diagnostic performance of CTderived fractional flow reserve for evaluation of myocardial ischaemia 
confirmed by invasive fractional flow reserve: a meta-analysis. Clin Radiol. 2015:70:476-486.

29. Arbab-Zadeh A, Miller JM, Rochitte CE, et al. Diagnostic accuracy of computed tomography coronary angiography according to pretest probability of coronary artery disease and severity of coronary arterial calcification. the core-64 (coronary artery evaluation using 64row multidetector computed tomography angiography) international multicenter study. J Am Coll Cardiol. 2012;59:379-387.

30. Abdulla J, Pedersen KS, Budoff M, Kofoed KF. Influence of coronary calcification on the diagnostic accuracy of 64-slice computed tomography coronary angiography: a systematic review and meta-analysis. Int $J$ Cardiovasc Imaging. 2012;28:943-953.

31. Nørgaard BL, Gaur S, Leipsic J, et al. Influence of coronary calcification on the diagnostic performance of CT angiography derived FFR in coronary artery disease: a substudy of the NXT trial. JACC Cardiovasc Imaging. 2015;9:1045-1055.

32. Kim KH, Doh JH, Koo BK, et al. A novel noninvasive technology for treatment planning using virtual coronary stenting and computed tomography-derived computed fractional flow reserve. JACC CardiovasC Interv. 2014:7:72-78.
33. Wang R, Renker M, Schoepf UJ, et al. Diagnostic value of quantitative stenosis predictors with coronary $\mathrm{CT}$ angiography compared to invasive fractional flow reserve. Eur J Radiol. 2015;84:1509-1515.

34. Renker M, Schoepf UJ, Wang R, et al. Comparison of diagnostic value of a novel noninvasive coronary computed tomography angiography method versus standard coronary angiography for assessing fractional flow reserve. Am J Cardiol. 2014;114:1303-1308.

35. Douglas PS, Pontone G, Hlatky MA, et al. Clinical outcomes of fractional flow reserve by computed tomographic angiography-guided diagnostic strategies vs. Usual care in patients with suspected coronary artery disease: the prospective longitudinal trial of FFRCT: outcome and resource impacts study. Eur Heart J. 2015;36:3359-3367.

36. Marwick TH, Cho I, Hartaigh B, Min JK. Finding the Gatekeeper to the Cardiac Catheterization Laboratory: Coronary CT Angiography or Stress Testing? J Am Coll Cardiol. 2015;65:2747-2756.

37. Hlatky MA, De Bruyne B, Pontone G, et al. Quality-of-Life and Economic Outcomes of Assessing Fractional Flow Reserve With Computed Tomography Angiography: PLATFORM. J Am Coll Cardiol. 2015;66:23152323. 